\title{
Comparative Pharmacokinetic Profile of Aceclofenac from Oral and Transidermal Application
}

\author{
Faiyaz Shakeel $^{1, *}$, Mohammed S Faisal ${ }^{2}$ and Sheikh Shafiq ${ }^{3}$ \\ ${ }^{1}$ Department of Pharmaceutics, Faculty of Pharmacy, Al-Arab Medical University, Benghazi-5341, Libya \\ ${ }^{2}$ Department of Pharmaceutics, Faculty of Pharmacy, Jamia Hamdard, Hamdard Nagar, New Delhi-110062, India \\ ${ }^{3}$ New Drug Delivery System (NDDS), Zydus Cadila Healthcare Ltd., Ahemdabad, Gujrat, India \\ *Corresponding author: Dr Faiyaz Shakeel, Department of Pharmaceutics, Faculty of \\ Pharmacy, Al-Arab Medical University, Benghazi-5341, Libya, \\ Tel: 00218-913899028; E-mail: faiyazs@fastmail.fm
}

Received March 22, 2009; Accepted April 17, 2009; Published April 25, 2009

Citation: Shakeel F, Mohammed SF, Shafiq S (2009) Comparative Pharmacokinetic Profile of Aceclofenac from Oral and Transdermal Application. J Bioequiv Availab 1: 013-017. doi:10.4172/jbb.1000003

Copyright: (C) 2009 Shakeel F, et al. This is an open-access article distributed under the terms of the Creative Commons Attribution License, which permits unrestricted use, distribution, and reproduction in any medium, provided the original author and source are credited.

\begin{abstract}
The aim of the present investigation was to compare pharmacokinetic profile (bioavailability) of aceclofenac by transdermal and oral application. Nanoemulsion, nanoemulsion gel and marketed tablet (Aceclofar ${ }^{\circledR}$ ) were subjected to pharmacokinetic (bioavailability) studies on Wistar male rats. Several pharmacokinetic parameters like $\mathbf{C}_{\text {max }}, t_{\text {max }}$, $\mathrm{AUC}_{0 \rightarrow \mathrm{t}}, \mathrm{AUC}_{0 \rightarrow \alpha}, \mathrm{K}_{\mathrm{e}}$, and $\mathrm{T}_{1 / 2}$ were determined for each formulation. The absorption of aceclofenac by transdermally applied nanoemulsion and nanoemulsion gel resulted in 2.95 and $\mathbf{2 . 6 0}$ fold increase in bioavailability as compared to oral tablet formulation. Results of these studies indicated that the nanoemulsions can be successfully used as potential vehicle for enhancement of bioavailability of aceclofenac.
\end{abstract}

Keywords: Aceclofenac; Nanoemulsion; Bioavailability

\section{Introduction}

Aceclofenac, a nonsteroidal anti-inflammatory drug (NSAID) has been recommended orally for the treatment of various kinds of pain, inflammation, rheumatoid arthritis and osteoarthritis (Gonzalez et al., 1994; Yamazaki et al., 1997; Yang et al., 2005; Shakeel et al., 2007). Long term oral administration of aceclofenac causes gastrointestinal (GI) ulcers and GI bleeding (Yamazaki et al., 1997). Transdermal route is known to reduce these adverse effects and increased bioavailability of drugs (Shakeel et al., 2007; Shakeel et al. 2008a, b, c). Aceclofenac is well absorbed orally with hepatic first pass metabolism (Gonzalez et al., 1994). It exhibits elimination half life of $4 \mathrm{~h}$, volume of distribution 251, $99 \%$ of protein binding and $60-70 \%$ of bioavailability after oral administration (Gonzalez et al., 1994). Recently lipid based carriers such as microemulsions, nanoemulsions, solid dispersions, solid lipid nanoparticles and liposomes have been used successfully for the enhancement of solubility/bioavailability of drugs (Kommuru et al., 2001; Shakeel et al., 2008b, c).
Nanoemulsions have been reported to make the plasma concentration profiles and bioavailability of drugs more reproducible (Lawrence and Rees, 2000; Kommuru et al., 2001; Shakeel et al., 2008b, c). Nanoemulsions have also been reported as one of the most promising techniques for enhancement of transdermal drug delivery and bioavailability of many drugs (Baboota et al., 2007a, b; Shafiq et al., 2007a, b; Shakeel et al., 2007; Shakeel et al., 2008a, b, c). Nanoemulsions are thermodynamically stable transparent or translucent solutions of oil and water stabilized by an interfacial film of surfactant and cosurfactant molecules having a droplet size 10-100 nm (Shafiq et al., $2007 \mathrm{a}, \mathrm{b}, \mathrm{c})$. This article evaluates the pharmacokinetic profile of aceclofenac using nanoemulsion technique and its comparison with marketed tablet formulation.

\section{Materials and Methods}

Materials

Aceclofenac was a kind gift sample from Ranbaxy Re- 
search Laboratory (Haryana, India). Oleolyl macroglycerides-EP (Labrafil) and diethylene glycol monoethyl ether (Transcutol-P) were gift sample from Gattefosse (Cedex, France). Glycerol triacetate (Triacetin) and acetonitrile (HPLC) grade were purchased from EMerck (Mumbai, India). Tween-80 was purchased from Sigma Aldrich (St. Luis, MO, USA). All other chemicals used in the study were of analytical reagent (AR) grade.

\section{Preparation of Aceclofenac Nanoemulsion and Nanoemulsion Gel}

Nanoemulsion formulation of aceclofenac (F1) was prepared by spontaneous emulsification method (Shakeel et al., 2007). $2 \% \mathrm{w} / \mathrm{w}$ of aceclofenac was dissolved in $15 \%$ w/w mixture of Labrafil and Triacetin (2:1, oil phase). Then $35.33 \% \mathrm{w} / \mathrm{w}$ of Tween- 80 and $17.66 \% \mathrm{w} / \mathrm{w}$ of Transcutol$\mathrm{P}$ were added slowly in the oil phase. The final formulation was made $100 \% \mathrm{w} / \mathrm{w}$ by slow addition of distilled (Shakeel et al., 2008a).

Nanoemulsions gel (NG1) was prepared by dispersing $1 \% \mathrm{w} / \mathrm{w}$ of Carbopol-940 in sufficient quantity of distilled water. After complete swelling of Carbopol-940 in distilled water. $2 \% \mathrm{w} / \mathrm{w}$ of aceclofenac was dissolved in $15 \% \mathrm{w} / \mathrm{w}$ mixture of Labrafil and Triacetin (2:1). Drug solution (aceclofenac) was added slowly to Carbopol-940 dispersion. $0.5 \% \mathrm{w} / \mathrm{w}$ of triethanolamine (TEA) was added in the above mixture to neutralize Carbopol-940. Then $35.33 \%$ w/w of Tween- 80 and $17.66 \%$ w/w of Transcutol-P were added slowly. Then remaining quantity of distilled water was added to get the final formulation $100 \% \mathrm{w} / \mathrm{w}$.

The composition of nanoemulsion (F1) and nanoemulsion gel (NG1) are given in Table 1.

\section{Characterization of Nanoemulsion}

Prepared nanoemulsion was characterized for surface morphology, droplet size, viscosity and refractive index. Surface morphology was determined using transmission electron microscopy (TEM) (Topcon, Paramus, NJ, USA). Droplet size distribution was determined by photon correlation spectroscopy using a Zetasizer 1000 HS (Malvern Instruments, Worchestershire, UK). Viscosity was determined using Cone and Plate viscometer (Brookfield Engineering Laboratories, Inc, Middleboro, MA). Refractive

\begin{tabular}{|l|c|c|}
\hline Ingredients & F1 & NG1 \\
\hline Aceclofenac $(\% \mathrm{w} / \mathrm{w})$ & 2.0 & 2.0 \\
\hline Carbopol-940 $(\% \mathrm{w} / \mathrm{w})$ & - & 1.0 \\
\hline Labrafil $(\% \mathrm{w} / \mathrm{w})$ & 10.0 & 10.0 \\
\hline Triacetin $(\% \mathrm{w} / \mathrm{w})$ & 5.0 & 5.0 \\
\hline Tween 80 & 35.33 & 35.33 \\
\hline Transcutol-P $(\% \mathrm{w} / \mathrm{w})$ & 17.66 & 17.66 \\
\hline Distilled water to $(\% \mathrm{w} / \mathrm{w})$ & 100.0 & 100.0 \\
\hline
\end{tabular}

Table 1: Compositions of nanoemulsion (F1) and nanoemulsion gel (NG1).
Research Article JBB/Vol.1 May-June 2009

index was determined using Abbes type Refractometer (Precision Standard Testing Equipment Corporation, Mumbai, India) (Shakeel et al., 2007).

\section{Pharmacokinetic Studies}

Approval to carry out pharmacokinetic studies was obtained from the local Animal Ethics Committee of Al-Arab Medical University, Benghazi, Libya. These studies were performed on optimized nanoemulsion (F1), nanoemulsion gel (NG1) and marketed tablet $\left(\right.$ Aceclofar $\left.^{\circledR}\right)$. Male Wistar rats were stores under standard laboratory conditions (temperature $25 \pm 2{ }^{\circ} \mathrm{C}$ and relative humidity of $55 \pm 5 \%$ ). The rats were kept in polypropylene cages (6/cage) with free access to standard laboratory diet. About $15 \mathrm{~cm}^{2}$ of skin was shaved on the abdominal side of rats in each group except group treated with marketed tablet formulation. They were fasted for the period of $12 \mathrm{~h}$ for observations of any unwanted effects. The dose for the rats was calculated according to the surface area ratio method (Shakeel et al., $2008 \mathrm{~b}, \mathrm{c})$. The rats were divided into 3 groups, each containing 6 rats. Group I received F1 transdermally, group II received NG1 transdermally and group III received marketed tablet orally. The dose for transdermal and oral treatment was similar. The rats were anaesthetized using light ether anesthesia and blood samples $(0.5 \mathrm{ml})$ were withdrawn from the tail vein of rat at 0 (pre-dose), 1, 2, 3, 6, 12 and 24 $\mathrm{h}$ in microcentrifuge tubes in which $6 \mathrm{mg}$ of EDTA was added as an anticoagulant. The blood collected was mixed with the EDTA properly and centrifuged at $5000 \mathrm{rpm}$ for 25 min for separation of plasma. The separated plasma was stored at $-21^{\circ} \mathrm{C}$ until drug analysis was carried out using high performance liquid chromatographic (HPLC) method.

\section{Sample Preparations}

Plasma samples were prepared by adding $500 \mu \mathrm{l}$ of plasma, $50 \mu \mathrm{l}$ standard solution of aceclofenac, $50 \mu \mathrm{l}$ of internal standard (IS) solution (diclofenac sodium), $1 \mathrm{ml}$ of orthophosphoric acid and $5 \mathrm{ml}$ of chloroform in small glass tubes. The tubes were vortex for $2 \mathrm{~min}$ and centrifuged for $25 \mathrm{~min}$ at $5000 \mathrm{rpm}$. Upper layer was discarded and the chloroform layer was transferred to a clean test tube and evaporated to dryness at $50^{\circ} \mathrm{C}$ under the stream of nitrogen. The residue was reconstituted with $100 \mu 1$ of mobile phase for HPLC analysis.

\section{Analysis of Aceclofenac}

Aceclofenac in plasma was determined by the reported validated HPLC method with slight modifications (Hinz et al., 2003). A Shimadzu model HPLC equipped with binary LC-10A VP pumps, variable wavelength programmable UV/ VIS detector SPD-10AVP column oven (Shimadzu), SCL 10AVP system controller (Shimadzu), Rheodyne injector fitted with a $20 \mu$ loop software was used for analysis. Analysis was performed on $\mathrm{C}_{18}$ RP-HPLC column. The mobile phase consisted of acetonitrile:phosphate buffer (40:60). The mobile phase was delivered at the flow rate of 
Research Article JBB/Vol.1 May-June 2009

$1.0 \mathrm{ml} / \mathrm{min}$. Detection was performed at $282 \mathrm{~nm}$. Injection volume was $20 \mu \mathrm{l}$. The concentration of unknown plasma samples was calculated from the calibration curve plotted between peak area ratios of aceclofenac to IS against corresponding aceclofenac concentrations.

\section{Pharmacokinetics and Statistical Analysis}

The plasma concentration of aceclofenac at different time intervals was subjected to pharmacokinetic (PK) analysis to calculate various parameters like maximum plasma concentration $\left(\mathrm{C}_{\text {max }}\right)$, time to reach maximum concentration $\left(\mathrm{T}_{\max }\right)$, area under the plasma concentration-time curve $\left(\mathrm{AUC}_{0 \rightarrow \mathrm{t}}\right.$ and $\left.\mathrm{AUC}_{0 \rightarrow \omega}\right)$, elimination half life $\left(\mathrm{T}_{1 / 2}\right)$ and eliminaon rate constant $\left(\mathrm{K}_{\mathrm{e}}\right)$. The values of $\mathrm{C}_{\text {max }}$ and $\mathrm{T}_{\max }$ were read directly from the arithmetic plot of time and plasma concentration of aceclofenac. The $\mathrm{AUC}_{0 \rightarrow t}$ was calculated by using the linear trapezoidal method. The $\mathrm{AUC}_{0 \rightarrow \omega}$ was calculated by using the equation:

$$
\mathrm{AUC}_{0 \rightarrow \omega}=\mathrm{AUC}_{0 \rightarrow \mathrm{t}}+\mathrm{C}_{\mathrm{t}} / \mathrm{K}_{\mathrm{e}}
$$

Where $\mathrm{C}_{\mathrm{t}}$ is the last measurable concentration and $\mathrm{K}_{\mathrm{e}}$ is elimination rate constant. $\mathrm{K}_{\mathrm{e}}$ was determined from the slope of linear portion of graph plotted between logarithm of plsma concentration and time. $\mathrm{T}_{1 / 2}$ was determined using the equation:

$$
\mathrm{T}_{1 / 2}=0.693 / \mathrm{K}_{\mathrm{e}}
$$

The relative bioavailability of aceclofenac after the transdermal administration versus the oral administration was calculated as follows:

$$
\mathrm{F} \%=\frac{\text { AUC sample }}{\text { AUC oral }} \bullet \frac{\text { Dose oral }}{\text { Dose sample }} \times 100
$$

The PK data was compared for statistical significance by one-way analysis of variance (ANOVA) followed by Tukey-Kramer multiple comparisons test using GraphPad Instat software (GraphPad Software Inc., CA, USA).

\section{Results and Discussions}

Nanoemulsion formulation of aceclofenac was successfully developed and characterized in terms of surface morphology, droplet size, viscosity and refractive index (Shakeel et al., 2007). Plasma concentration of aceclofenac from formulations F1, NG1 and marketed tablet at different time intervals was determined by reported HPLC method (Hinz et al., 2003). The graph between plasma aceclofenac concentration and time was plotted for each formulation (Figure 1). It was seen from Figure 1 that the plasma concentration profile of aceclofenac for F1 and NG1 showed greater improvement of drug absorption than the oral tablet formulation. Peak (maximum) plasma concentration $\left(\mathrm{C}_{\max }\right)$ of aceclofenac in F1, NG1 and tablet was $9.4 \pm 1.1,8.8 \pm 0.89$ and $10.2 \pm 3.4 \mu \mathrm{g} / \mathrm{ml}$ respectively whereas $\mathrm{t}_{\text {max }}$ was $6 \pm 0.31$,

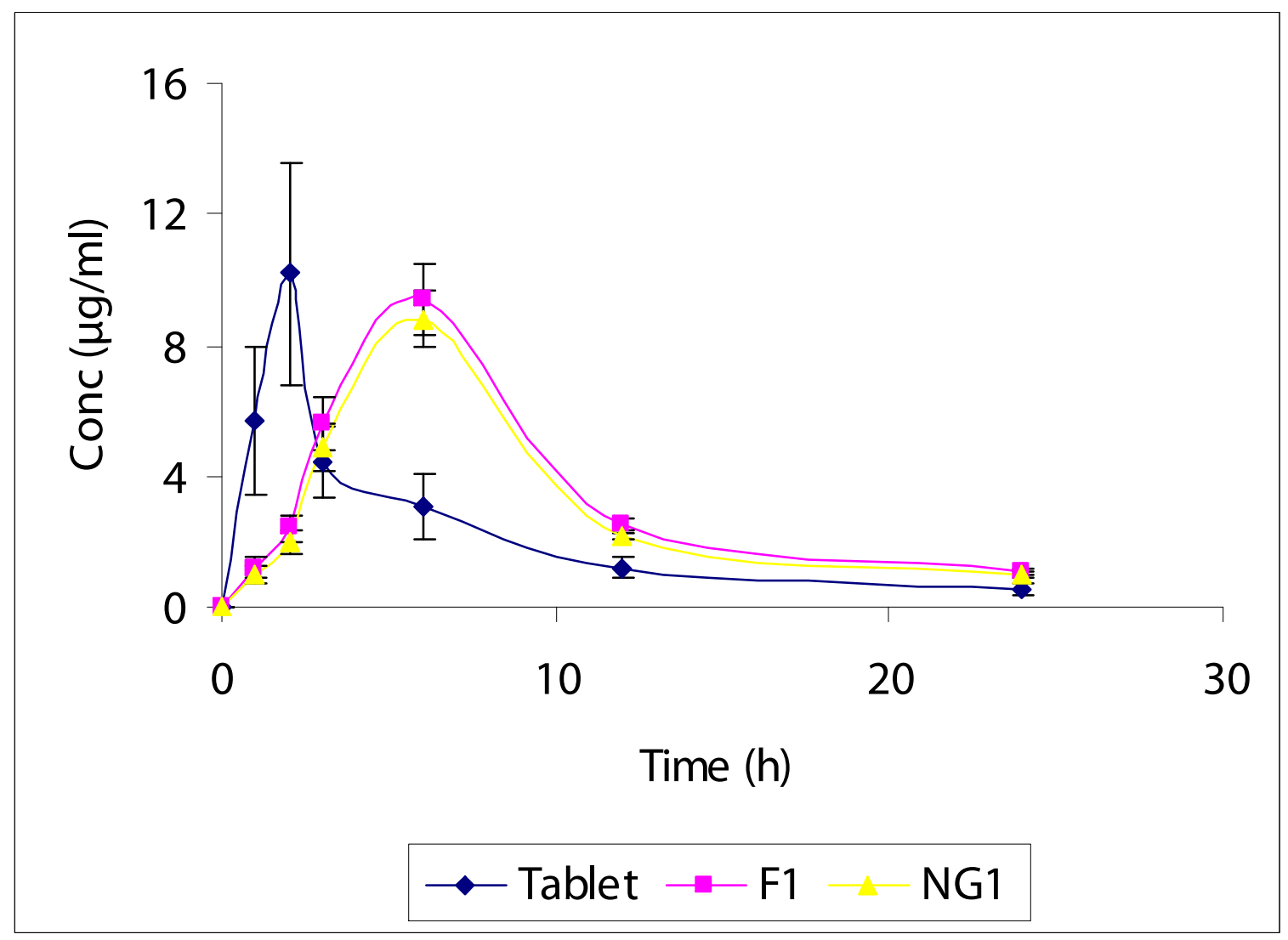

Figure 1: Plasma concentration (Mean $\pm S D$ ) time profile curve of aceclofenac from F1, NG1 and tablet $(n=6)$. 
$6 \pm 0.34$ and $2 \pm 0.27 \mathrm{~h}$ respectively (Table $2 \&$ Figure 1 ). $\mathrm{AUC}_{0 \rightarrow \mathrm{t}}$ and $\mathrm{AUC}_{0 \rightarrow \omega}$ in formulations $\mathrm{F} 1, \mathrm{NG1}$ and tablet were $61.42 .98,54.2 \pm 2.58$ and $20.8 \pm 3.5 \mu \mathrm{g} . \mathrm{h} / \mathrm{ml}$ respectively and $77.5 \pm 3.1,69.4 \pm 2.85$ and $29.1 \pm 4.2 \mu \mathrm{g} . \mathrm{h} / \mathrm{ml}$ respectively (Table 2). These pharmacokinetic parameters $\left(\mathrm{C}_{\max }, \mathrm{t}_{\max }, \mathrm{AUC}_{0 \rightarrow \mathrm{t}}\right.$ and $\left.\mathrm{AUC}_{0 \rightarrow \omega}\right)$ obtained with formulations $\mathrm{F} 1$ and NG1 were significantly different from those obtained with oral tablet formulation $(\mathrm{P}<0.05)$. This indicated that transdermal application can significantly modify pharmacokinetic profile of aceclofenac. The significant AUC values observed with F1 and NG1 also indicated increased bioavailability of the aceclofenac from F1 and NG1 in com- parison with oral tablet formulation $(\mathrm{P}<0.05)$. The $\mathrm{K}_{\mathrm{e}}$ and $\mathrm{T}_{1 / 2}$ for $\mathrm{F} 1$, NG1 and tablet were found $0.154,0.152$ and $0.159 \mathrm{~h}^{-1}$ respectively $\& 4.50,4.55$ and $4.35 \mathrm{~h}$ respectively (Table 2). There was no significant variation in $\mathrm{K}_{\mathrm{e}}$ and $\mathrm{T}_{1 / 2}$ for F1, NG1 when compared with tablet formulation $(\mathrm{P} \geq 0.05)$. This indicated that transdermal application could not change intrinsic pharmacokinetic parameters such as $\mathrm{K}_{\mathrm{e}}$ and $\mathrm{T}_{1 / 2}$. The formulations $\mathrm{F} 1$ and NG1 were found to enhance the bioavailability of aceclofenac by 2.95 and 2.60 folds (percent relative bioavailability 295 and 260) with reference to the oral tablet formulation (Table 2). This increased bioavailability from transdermal formulations (F1

\begin{tabular}{|c|c|c|c|c|c|c|c|}
\hline Formulation & $\begin{array}{l}t_{\max } \pm S D \\
\text { (h) }\end{array}$ & $\begin{array}{l}\mathrm{C}_{\max } \pm \mathrm{SD} \\
(\mu \mathrm{g} / \mathrm{ml})\end{array}$ & $\begin{array}{l}\mathbf{A U C} \mathbf{C}_{0 \rightarrow \mathrm{t}} \pm \mathrm{SD} \\
(\mu \mathrm{g} \cdot \mathbf{h} / \mathbf{m l})\end{array}$ & $\begin{array}{l}\mathrm{AUC}_{0 \rightarrow \alpha^{ \pm}} \mathbf{S D} \\
(\mu \mathrm{g.h} / \mathbf{m l})\end{array}$ & $K_{e}\left(h^{-1}\right)$ & $\begin{array}{l}T_{1 / 2} \\
\text { (h) }\end{array}$ & $\begin{array}{l}F \\
\% \\
\end{array}$ \\
\hline F1 & $6^{*} \pm 0.31$ & $9.4^{*} \pm 1.1$ & $61.4^{*} \pm 2.98$ & $77.5^{*} \pm 3.1$ & 0.154 & 4.50 & 295 \\
\hline NG1 & $6^{*} \pm 0.34$ & $8.8^{*} \pm 0.89$ & $54.2 * \pm 2.58$ & $69.4^{*} \pm 2.85$ & 0.152 & 4.55 & 260 \\
\hline Tablet & $2 \pm 0.27$ & $10.2 \pm 3.4$ & $20.8 \pm 3.5$ & $29.1 \pm 4.2$ & 0.159 & 4.35 & --- \\
\hline
\end{tabular}

$* \mathrm{p}<0.05$ when compared with tablet formulation using one way ANOVA followed by Tukey Krammer multiple comparison test $\mathrm{t}_{\max }$ is time of peak concentration, $\mathrm{C}_{\max }$ is peak of maximum concentration, $\mathrm{AUC}_{0 \rightarrow \mathrm{t}}$ is area under the concentration time profile curve until last observation, $\mathrm{AUC}_{0 \rightarrow \alpha}$ is area under the concentration time profile curve from time 0 to infinity, $\mathrm{K}_{\mathrm{e}}$ is elimination rate constant, $\mathrm{T}_{1 / 2}$ is elimination half life and $\mathrm{F}$ is relative bioavailability

Table 2: Relative bioavailability and mean pharmacokinetic parameters $( \pm \mathrm{SD}, \mathrm{n}=6)$ of aceclofenac from $\mathrm{F} 1$, NG1 and marketed tablet.

and NG1) may be due to the enhanced skin permeation and avoidance of hepatic first pass metabolism of aceclofenac in the form of transdermal formulations.

\section{Conclusion}

These studies revealed significantly greater extent of absorption of aceclofenac than the oral tablet formulation $(\mathrm{P}<0.05)$. The absorption of aceclofenac from $\mathrm{F} 1$ and NG1 resulted in 2.95 and 2.60 fold increases in bioavailability as compared to the oral tablet formulation. Results of these studies indicate that nanoemulsions can be successfully used for enhancement of bioavailability of aceclofenac.

\section{Acknowledgements}

The authors are also thankful to Gattefosse (France) for donating gift samples of oils, surfactants and cosurfactants respectively.

\section{References}

1. Baboota S, Shakeel F, Ahuja A, Ali J, Shafiq S (2007a) Design development and evaluation of novel nanoemulsion formulation for transdermal potential of celecoxib. Acta Pharm 8: 316-332." CrossRef

» Pubmed " Google Scholar

2. Baboota S, Alazaki A, Kohli K, Ali J, Dixit N, Shakeel F (2007b) Development and evaluation of a microemulsion formulation for transdermal delivery of terbenafine. PDA J Pharm Sci Tech 61: 276-285.

» CrossRef " Pubmed Google Scholar
3. Gonzalez E, Cruz C, Nicolas R, Egido J, Herrero-Beaumont $G$ (1994) Long-term effects of nonsteroidal antiinflammatory drugs on the production of cytokines and other inflammatory mediators by blood cells of patients with osteoarthritis. Agents Actions 41: 171-178.

"CrossRef " Pubmed Google Scholar

4. Hinz B, Auge D, Rau T, Reitbrock S, Brune K, et al. (2003) Simultaneous determination of aceclofenac and three of its metabolites in human plasma by high performance liquid chromatography. Biomed Chromatogr 17: 268-275. "CrossRef " Pubmed " Google Scholar

5. Kommuru TRK, Gurley B, Khan MA, Reddy IK (2001) Selfemulsifying drug delivery systems (SEDDS) of coenzyme Q10: Formulation development and bioavailability assessment. Int J Pharm 212: 233-246.

»CrossRef » Pubmed " Google Scholar

6. Lawrence MJ, Rees GD (2000) Microemulsion-based media as novel drug delivery systems. Adv Drug Deliv Rev 45: 89-121. " CrossRef " Pubmed " Google Scholar

7. Shafiq S, Shakeel F, Talegaonkar S, Ahmad FJ, Khar RK, et al. (2007a) Design and development of oral oil in water ramipril nanoemulsion formulation: In vitro and in vivo assessment. J Biomed Nanotech 3: 28-44.

»CrossRef " Pubmed Google Scholar

8. Shafiq S, Shakeel F, Talegaonkar S, Ahmad FJ, Khar RK, et al. (2007b) Development and bioavailability as- 
sessment of ramipril nanoemulsion formulation. Eur J Pharm Biopharm 66: 227-242. " CrossRef " Pubmed

" Google Scholar

9. Shafiq S, Shakeel F, Talegaonkar S, Ali J, Baboota S, et al. (2007c) Formulation development and optimization using nanoemulsion technique: a technical note. AAPS Pharm Sci Tech 8: E28. " CrossRef " Pubmed

" Google Scholar

10. Shakeel F, Baboota S, Ahuja A, Ali J, Aqil M, et al. (2007) Nanoemulsions as vehicles for transdermal delivery of aceclofenac. AAPS Pharm Sci Tech 8: E104. " CrossRef

» Pubmed " Google Scholar

11. Shakeel F, Baboota S, Ahuja A, Ali J, Shafiq S (2008a) Skin permeation mechanism of aceclofenac using novel nanoemulsion formulation. Pharmazie 63: 580-584.

"CrossRef " Pubmed " Google Scholar

12.Shakeel F, Baboota S, Ahuja A, Ali J, Shafiq S (2008b)
Skin permeation mechanism and bioavailability enhancement of celecoxib from transdermally applied nanoemulsion. J Nanobiotech 6: E8. " CrossRef

" Pubmed " Google Scholar

13. Shakeel F, Baboota S, Ahuja A, Ali J, Shafiq S (2008c) Celecoxib nanoemulsion: Skin permeation mechanism and bioavailability assessment. J Drug Target 16: 733740. " CrossRef " Pubmed " Google Scholar

14.Yamazaki R, Kawai S, Mastsuzaki T, et al. (1997) Aceclofenac blocks prostaglandin E2 production following its intracellular conversion into cyclooxygenase inhibitors. Eur J Pharmacol 329: 181-187. » CrossRef

" Pubmed " Google Scholar

15. Yang JH, Kim Y, Kim KM (2002) Preparation and evaluation of aceclofenac microemulsion for transdermal delivery system. Arch Pharm Res 25: 534-540. ” CrossRef

» Pubmed " Google Scholar 